Laurens van Krevelen

Laurens van Krevelen: Oud-uitgever/ directeur van Uitgeverij J.M. Meulenhoff Amsterdam. Thans voorzitter van de Stichting Bibliotheek van het Boekenvak, die samenwerkt met de Bibliotheek Bijzondere Collecties van de Universiteit van Amsterdam bij de ontsluiting van Nederlandse boekhistorische archieven. E-mail krevelen@xs4all.nl

\title{
De creatieve bewegingen van een vrije geest: aantekening over het contrast tussen Breytenbach's integrale werkwijze en de gefragmenteerde perceptie van zijn werk
}

\section{Creative movements of a free mind: Notes on the discrepancy between Breytenbach's inte- grated creative process and the fragmented perception of his work.}

Breyten Breytenbach's multiple and many-sided work ranges from poetry, fiction, drama and essay to drawing, print and painting an cultural reasearch and activism. He has always emphasized that his varied activities and expressions are essentially one integrated art of living and thinking. However, the public and critical perception of Breytenbach's work tends to ignore its fundamental interconnections, reducing it to loose, fragmented aspects. Key words: Breyten Breytenbach, creative process, creative theory, pluriformity, public perception, critical perception.

Het veelsoortige en veelzijdige werk van Breyten Breytenbach strekt zich uit van poëzie, verhalend proza, drama en essay tot tekenen, grafiek, schilderen en culturele vernieuwing en activisme. ${ }^{1}$ Zelf heeft hij altijd de wezenlijke eenheid van zijn activiteiten en experimenten benadrukt, maar de publieke en kritische perceptie van zijn werk lijkt de fundamentele samenhang daarvan te miskennen, en reduceert het tot gefragmenteerde, op zichzelf staande aspecten.

\section{Poëzie is levenskunst}

Als Breyten Breytenbach alleen maar poëzie had geschreven was zijn schrijverschap al uitzonderlijk en belangwekkend geweest, maar hij schreef in dezelfde adem ook verhalen, romans, reisjournaals, essays, toneelstukken, politieke analyses en manifesten, en tegelijkertijd schiep hij een wonderbaarlijk beeldend oeuvre van schilderijen, tekeningen en grafiek dat een eigen plaats inneemt in de hedendaagse kunst. Als hij nooit iets geschreven zou hebben, zou hij als beeldend kunstenaar stellig even bekend zijn geworden.

Daarnaast was hij de bezielende kracht van de politieke verzetsgroep Okhela in de jaren van strijd tegen het apartheidsregime in zijn geboorteland, wat hem een gevangenisstraf van ruim zeven jaren (1975-82) kostte wegens het plegen van "terroris- 
tische" misdrijven. In het verlengde van die politieke activiteiten gedurende de jaren zestig en zeventig ligt de oprichting van het Gorée Institute in 1992, waarvan Breytenbach de bedenker is geweest (en waarvan hij nog steeds de leiding heeft). Het Gorée Institute, gevestigd op het kleine eiland Gorée, vlak voor de Senegalese kust bij Dakar - het was ooit de West-Afrikaanse overslaghaven voor de slavenhandel van de WestIndische Compagnie - tracht de culturele samenwerking op het Afrikaanse continent te bevorderen en de raciale, etnische en ideologische tegenstellingen te overbruggen om de basisvoorwaarden voor open democratische samenlevingen te scheppen. Op Gorée vinden opzienbarende conferenties en workshops plaats die op den duur hun invloed op de eigen culturele identiteit van Afrika niet zullen missen. ${ }^{2}$ Als Breytenbach alleen maar het Gorée Institute tot stand had gebracht zonder ooit te schrijven of te schilderen, zou zijn unieke betekenis voor de culturele ontwikkeling van Afrika al een uitvoerige biografie rechtvaardigen.

Sinds 1998 is Breytenbach bovendien deeltijds "Distinguished Professor" in creative writing aan de New York University, een betrekking die hij nog steeds met grote toewijding vervult. Zijn colleges worden door vele studenten gevolgd en sommigen zijn succesvolle schrijvers geworden. Uit de discussies met studenten is zijn stimulerende "schrijfboek" Intimate Stranger voortgekomen. ${ }^{3}$

Breytenbach heeft het klaargespeeld al die verschillende creatieve identiteiten tegelijkertijd te verwezenlijken, met bij elk dezelfde bijzondere overgave, veelzijdigheid en originaliteit. De vraag dringt zich dan op hoe al deze identiteiten zich tot elkaar verhouden: hoe verhoudt zijn poëzie zich tot zijn proza, essays en manifesten, hoe zijn literaire werk tot zijn schilderijen en tekeningen, hoe zijn artistieke productie tot zijn politieke activiteiten en zijn inzet voor de continentale Afrikaanse cultuur en samenleving?

Het antwoord op die vragen heeft Breytenbach in zijn essays en interviews vele malen gegeven. Al die uitingen zijn in feite één geïntegreerd geheel, er is daartussen dan ook geen hiërarchie, geen tegenstelling en geen scheiding. Het spreekt vanzelf dat er verschillen zijn in vorm en in middelen, in de gebruikte taal en in de daarmee bereikte resultaten. Niet zonder ironie schreef hij in een essay van 1996: "Poëzie is geen kunstvorm, ze is een levensdiscipline," en daarbij doelde hij zeker op zijn eigen poëzie, al is het een criterium dat hij op alle poëzie toepast. ${ }^{4}$ Dat credo gaat in tegen de gangbare opvatting dat een gedicht (evenals elk kunstwerk) een geïsoleerd organisme is, een los esthetisch "ding". Breytenbach verdedigt daarentegen de stelling dat kunstwerken spiegels, instrumenten zijn waarmee het inzicht in de werkelijkheid en het leven kan worden vergroot. Dezelfde stelling keert in wat andere bewoordingen terug in zijn al genoemde "schrijfboek" van 2005, waarin hij het woord "poëzie" verving door "schrijven" en "levensdiscipline" door "levenskunst". "Schrijven is geen kunstvorm, het is een levenskunst," schreef hij toen (Breytenbach 2005: 182). Datzelfde zou hij ook hebben kunnen zeggen over tekenen en schilderen, zelfs over zijn politieke idealen. 
Het gaat Breytenbach blijkbaar niet om de "objectieve" poëtische kunstwerken, die ontstaan uit het creatieve proces, maar om de levensdiscipline, omdat die de echte kunst is die tot inzicht en visie kan leiden - niet alleen bij de maker maar evenzeer bij de lezer of beschouwer. Zijn gedichten zijn evenals zijn verhalen, essays, schilderijen en politieke denkbeelden hartstochtelijke blijken van bevrijdende discipline en levenskunst. Zijn werk laat zich niet begrenzen en opsluiten in een esthetisch kader; het is geen "product" dat voorgoed voltooid is. "Poëzie is een proces," schreef hij in verschillende essays - ook hier verwisselde hij het woord "poëzie" soms door "schrijven" of "schilderen"; hij had er evengoed "denken" en "leven" voor in plaats kunnen stellen.

De sleutel tot zijn levensdiscipline is de vrije verbeeldingskracht. "Via de verbeelding kun je de 'werkelijkheid' benaderen en je toe-eigenen. Begrip is een sprong in de verbeelding," schrijft hij in Intimate Stranger (Breytenbach 2005: 173). Dat leidende beginsel is in allerlei variaties terug te vinden in zijn eerdere boeken. Geen bewustwording zonder vrije verbeelding.

\section{Dichter/outsider en publieke persoon}

Vanaf zijn eerste twee boeken, die ysterkoei moet sweet (gedichten) en Katastrofes (prozagedichten), die beide in 1964 zijn verschenen, viel Breytenbach niet alleen op als drastische vernieuwer van de poëtische taal en verbeelding, maar ook als de brenger van nieuwe idealen en een kritische maatschappijvisie in het door de apartheid verstarde Zuid-Afrika. Van meet af aan werd hij daardoor tot een publieke persoon gemaakt in zijn geboorteland, ook al leefde hij toen al meer dan vijf jaren in Parijs. Francis Galloway heeft in haar lucide boek Breyten Breytenbach as openbare figuur een gedetailleerde analyse gegeven van de heftige reacties die alle uitingen van Breytenbach steeds weer teweeg brachten in de gehele Zuid-Afrikaanse samenleving van de jaren zestig en zeventig: zijn werk werd - vooral door de jonge generatie van toen extreem bewonderd, en tegelijk extreem verguisd; dat laatste vooral door de gezeten burgerij op een wijze zoals geen andere schrijver te beurt was gevallen. Breytenbach gaf bovendien in de Zuid-Afrikaanse pers op welsprekende wijze uiting aan zijn kritiek op het apartheidsregime zoals nog niemand van de "eigen" Afrikaner gemeenschap toen had gedaan: hij dwong zijn landgenoten tot zelfonderzoek, zoals Francis Galloway concludeert - al was lang niet iedereen daartoe bereid; die anderen raakten buiten zichzelf van woede door de meedogenloze spiegels die hij hun voorhield (Galloway 1990).

Het terrorisme-proces, dat in 1976 met veel vertoon in Pretoria tegen Breytenbach werd gevoerd, en zijn veroordeling tot negen jaar gevangenisstraf, maakten hem van een publiek persoon in eigen land tot een bekende naam in de gehele wereld. In vele landen ontstonden comités die zijn vrijlating bepleitten. De internationale schrij- 
versvereniging PEN en de mensenrechtenorganisatie International Commission of Jurists for Human Rights "adopteerden" zijn zaak. Mede ten gevolge van internationale politieke druk, vooral van de regeringen van de Duitse Bondsrepubliek en Frankrijk, op Zuid-Afrika werd hij in december 1982 vervroegd vrijgelaten. In de jaren van zijn gevangenschap verscheen zijn werk in vele talen, maar toch was de aandacht voor zijn bijzondere literaire betekenis bij lange na niet even groot als voor zijn politieke verzetsactiviteiten.

Toen Breytenbach weer op vrije voeten was, en hij door de Franse president François Mitterand tot Frans staatsburger was gemaakt, schreef hij eerst zijn herinneringen aan de duistere gevangenisjaren. Zijn magistrale boek The True Confessions of an Albino Terrorist dat in 1984 verscheen, maakte in vele landen grote indruk. Hij was daarmee meteen een "wereldnaam" geworden op de internationale boekenmarkt. Het bijzondere van dat boek is, dat het niet alleen een beklemmend beeld geeft van de onvoorstelbare, wrede wereld van de Zuid-Afrikaanse gevangenissen van die jaren, en ook een indringende zelfreflectie is over alles wat hem daar overkwam, maar dat het tegelijk een literair meesterwerk is geworden, vol droombeschrijvingen, poëtische invallen, en allerlei virtuoze, komische en lyrische passages over medegevangenen en vrienden. The True Confessions is een hoogst persoonlijk credo met vermijding van alle kenmerken van de sensationele reportage.

Toch bleef de dichter en schrijver Breytenbach desondanks vooral gelden als een politieke activist; de pers bleek steeds nagenoeg alleen geïnteresseerd te zijn in zijn meningen over de politieke transformatie van Zuid-Afrika. Voor tal van kranten en tijdschriften in Engeland, Frankrijk, Nederland, België en Duitsland schreef hij op verzoek politieke commentaren en essays. Ook de literaire kritiek op zijn werk bleef grotendeels gefixeerd op de politieke aspecten. Dat een groot deel van zijn poëzie gevormd wordt door meeslepende liefdeslyriek en ongeëvenaarde meditatieve visoenen is door de nadruk op de opstandige lading van veel andere gedichten op de achtergrond geraakt. Wanneer er nieuwe boeken of dichtbundels van hem werden gepresenteerd, vroeg de pers hem vooral zijn mening over politieke actualiteiten, als was hij een reizend verslaggever en niet één van de grote dichters van deze tijd.

Door sommigen is daarom de vraag opgeworpen of Breytenbach als dichter internationaal wel even bekend zou zijn geworden, als hij geen publieke persoon zou zijn geweest. Een dergelijke vraag is natuurlijk niet te beantwoorden, want Breytenbachs radicale politieke attitude heeft altijd een onlosmakelijke deel uitgemaakt van zijn literaire activiteit. Toch is het meer dan waarschijnlijk dat Breytenbach internationaal zeker ook grote faam had verworven als hij uitsluitend literair werk had gemaakt zonder een politieke rol te spelen. Zijn werk bezit immers een uitzonderlijke toon, kwaliteit en kracht die onder alle omstandigheden erkend zouden zijn. Misschien zou zijn literaire reputatie dan wellicht, om de speculatie nog even voort te zetten, toch een wat andere "lading" hebben gekregen dan nu het geval is. De "publieke" reputatie van politiek 
activist, die vooral gevormd is in een omgeving die gewoonlijk de waarde van creatieve processen zoals poëzie volstrekt ontkent en afwijst, zou in dat geval zijn literaire betekenis en de veelzijdigheid van zijn dichterschap niet hebben "gestoord".

Waarmee niet gezegd wil zijn, dat Breytenbach als dichter ten gevolge van zijn "publieke" naam geen grote waardering geniet van collega-dichters in tal van landen. Wel is er een enorme discrepantie tussen de serieuze waardering van individuele collega's en geestverwanten, en de massale maar doorgaans oppervlakkige, fragmentarische aandacht voor zijn politieke visies en acties. Als dichter en schrijver is Breytenbach, ondanks het kortstondige wereldsucces met zijn buitengewone boek The True Confessions of an Albino Terrorist, op de eenzame hoogte gebleven die het lot van elk waarachtig dichterschap lijkt te zijn. Zijn publieke bekendheid heeft zijn artistieke eenzaamheid wellicht zelfs groter gemaakt.

\section{De wind van de tijd}

In een vroeg essay over Breytenbachs poëzie dat in 1972 verscheen (derhalve lang voor het breukvlak van zijn arrestatie, proces en gevangenschap) heeft $\mathrm{H}$. C. ten Berge de nadruk gelegd op de daarin vaak voorkomende thematiek van vervreemding/ ontheemdheid / ballingschap / geïsoleerdheid (Ten Berge 1972).

Breytenbach heeft sinds 1960, vanaf zijn tweeëntwintigste jaar, steeds buiten zijn geboorteland geleefd - afgezien van de zeven jaren van verschrikking waarin hij onvrijwillig verbleef in Zuid-Afrikaanse gevangenissen; die jaren kunnen beslist niet gelden als een periode van remigratie. Hoezeer Breytenbachs poëzie en zijn andere werk door het land en de mensen van Zuid-Afrika zijn geïnspireerd, zijn blik daarop is onmiskenbaar de blik van een buitenstaander, van een "balling".

Het woord "ballingschap" heeft hij zelf in tal van essays en voordrachten van voor 1975, het jaar van zijn arrestatie, ook zelf meermaals gebruikt om zijn eigen positie als dichter en schrijver te typeren, hoewel hij in letterlijke zin natuurlijk geen "balling" was, maar een emigrant uit vrije wil. In een lezing die hij in 1972 hield over vrijheid en ballingschap zei hij dat "ballingschap" een "land" kan worden waarin de schrijver zich sterker bewust wordt van de eigen taal en van de sociale werkelijkheid van zijn land van herkomst; "hij heeft het voorrecht om de vrijheid van de ballingschap naar beste kunnen te gebruiken ten bate van de strijd in zijn land" (Breytenbach 1986a: 74-6). ${ }^{5}$ Onder de titel "' $n$ Blik van buiten" hield hij in 1973 in Zuid-Afrika een historische toespraak tijdens een universitair symposium over de literaire generatie van de Zestigers, de generatie waartoe hij zelf wordt gerekend. Hij gaf die voordracht gedurende het veelbewogen verblijf van drie maanden in Zuid-Afrika, dat hij zo indrukwekkend beschreven heeft in het boek ' $n$ Seisoen in die paradys. ${ }^{6}$ Breytenbach kwalificeerde de bedoelde toespraak bij voorbaat als "een zeer extremistische lijkrede"; zij had dan ook het onmiddellijke effect van een donderpreek, van vloeken in de 
kerk. Hij wees op de vervreemding waarin de apartheid de Afrikaanse literatuur had gemanoeuvreerd, en hij kondigde tegelijkertijd het reddeloze en roemloze einde aan van het apartheidsland: “Wij hebben allemaal samen, ijverig en blindelings, dit land tot aan de laatste afgrond voor de hel gesleept." Aan het slot veroordeelde hij alle literatuur en poëzie die de ogen sluit voor de werkelijkheid:

Toen gedichten maken 'dichtkunst' werd, zijn ook de tanden eruit getrokken. Het is een esthetisch ding geworden dat alleen maar naar zichzelf of naar andere literatuur wil verwijzen. We zetten het op een boekenplankje, veilig tussen andere bandjes waar het niet kan bijten, nu is het voedsel voor de tor en de literator; geen bedreiging meer voor de bestaande orde, geen werktuig of wapen' (Breytenbach 1976: 127). ${ }^{7}$

Veel van Breytenbachs poëzie wil wel degelijk een werktuig te zijn en soms zelfs een wapen, waarmee de schrijver en vervolgens de lezer zich bewust kunnen worden van de werkelijkheid en van alles wat deze werkelijkheid vervalst en geweld aandoet. Op die wijze wordt poëzie opnieuw bedreigend voor gemakzuchtige gemoedsrust, en dus werkt zij dan ook vervreemdend; ze voert de lezer een soort ballingschap binnen vanuit de ogenschijnlijk veilige maar grondig verziekte realiteit. Vervreemding is onvermijdelijk bij elk werktuig dat tot bewustwording aanzet.

Over Breytenbachs vervreemdingstechnieken schreef J. M. Coetzee in 1991 het verhelderende essay "Breyten Breytenbach and the reader in the mirror". Coetzee constateerde dat er een voortdurende "verwisseling tussen het ik en de ander" plaats vindt in Breytenbachs poëzie: "het is niet duidelijk wat het $i k$ is, en wat een beeld." De stem van de dichter, zegt Coetzee, worstelt bij het in- en uitademen met innerlijke aanklachten; "hij schrijft tegen en kan niet schrijven zonder een veelheid van verinnerlijkte weerstanden die in wezen niet anders zijn dan een verinnerlijkte censortweelingbroer, op wie hij gesteld is en die hij tegelijk haat." De bewustwording waar Breytenbachs poëzie de dichter zelf toe brengt is, volgens Coetzee, "de opdracht om met zijn daimon en met zijn demonen te leren leven." Die opdracht wordt door de dichter aan de lezer doorgegeven. (Coetzee 2004: 88, 93, 94). ${ }^{8}$

Toch is Breytens poëzie nog veel complexer en veelzijdiger (en vooral veel vrijer) dan alleen die vormen van bewustwording. Poëzie is "de adem van het gewaar worden, en het ademen daarin," schreef Breytenbach in zijn boek Intimate Stranger. "Poëzie is ook de wind van de tijd en derhalve de beweging en zang van het zijn" (Breytenbach 2005: 13). De onrustbarende tijd waarin wij leven en die wij voortdurend inademen, of wij dat willen of niet, vormt de inspiratie van Breytenbachs even paradijselijke als demonische poëzie.

Breytenbachs "queeste" leidde hem niet, zoals in Dante's Goddelijke Komedie het geval is, van de hel via de louteringsberg naar het paradijs, maar zij begon met een moedwillige prijsgave van ieder paradijs, om via een hel van beproevingen het nooit 
meer eindigende vagevuur van de riskante "middenwereld" te bereiken, met alle angsten, dromen en verrukkingen. De filosofisch getoonzette woorden waarmee hij op 20 januari 2006 het literatuurfestival "Winternachten" in Den Haag opende, sloot hij af met een bijna mythische aansporing: “Dit moet het zijn! Ga verder, ga naar de uiterste rand van het denken, naar waar de hand zingt. Want wie of wat kunnen je naar de onderwereld voeren behalve de creatieve bewegingen van de vrije geest?" Hij neemt darbij de blijkbaar onvermijdelijke fragmentatie van de schepping in de triviale publieke "middenwereld" op de koop toe.

\section{Noten}

1. Deze beschouwing is een bewerking van het nawoord bij de in Nederland gepubliceerd eigen keuze van Breyten Breytenbach uit zijn gehele dichtwerk, verschenen onder de titel De windvanger.

2. Zie voor de activiteiten van het Gorée Institute de website www.goreeinstitute.org.

3. Intimate Stranger. A Writing Book, verscheen tot dusverre nog alleen in het Nederlands als Intieme Vreemde. Een schrijfboek (2005). De oorspronkelijk in het Engels geschreven tekst zal naar verwachting in 2009 verschijnen bij Archipelago Books, Brooklyn, NY.

4. Ontleend aan de niet gepublieerde "Van Gogh-lezing", die hij onder de titel "Cadavre exquis" op 26 juni 1996 in Den Bosch uitsprak.

5. "Losse opmerkingen over vrijheid en ballingschap", tekst van en lezing uit 1972, gebundeld in het boek End Papers; in het Nederlands verschenen als De andere kant van de vrijheid (1986).

6. De tekst van "'n Blik van buite" werd later opgenomen in het boek ' $n$ Seisoen in die paradys (1976).

7. “Toe gedigte maak' $n$ 'digkuns' geword het is sy tande getrek. Dit het 'n estetiese ding geword wat net na homself of na ander literatuur verwys; ons sit dit op 'n rakkie tussen veilige omslae neer, waar dit nie kan byt nie, nou is dit kos vir akkedisse en die akkademici; dis nie meer 'n bedreiging vir die bestaande orde, 'n werktuig of 'n wapen nie" (Breytenbach 1976: 127).

8. "[...] the interchange between self and other is, in effect, continuous" (88); “[...] it is not clear what is self, what image" (88); "[...] [he] writes against and cannot write without a manifold of internalized resistances that are in essence no different from an internalized censor-twin, both cherished and hated'(93); “The poems that emerged with him from prison into the fresh air point to a much harder task: that of living with his daimon and his demons" (94) (Coetzee 2004).

9. De titel van deze ongepubliceerde lezing uit 2006 is: "Thinking Birdness". Het Haagse festival "Winternachten" plaatste destijds de door Krijn Peter Hesselink vervaardigde vertaling daarvan, "Een bespiegeling op vogeljachtigheid", op het webjournal www.powerofculture.nl (daar nu niet meer beschikbaar).

\section{Bibliografie}

Berge, H. C. ten. 1972. Een nabericht over het werk van Breyten Breytenbach. In Breyten Breytenbach. Skryt. Amsterdam: Meulenhoff, 59-69.

. 1980 [1972]. Dichter zonder taal, schilder zonder ogen. Levenstekens \& Doodssinjalen. Amsterdam: De Bezige Bij, 285-310.

Breytenbach, Breyten. 1976. ' $n$ Seisoen in die paradys, Kaapstad: Perskor. 1986a. End Papers. London: Faber \& Faber.

1986b. De andere kant van de vrijheid. Amsterdam: Van Gennep.

1996. Cadavre exquis - Van Gogh-lezing. Den Bosch. Ongepubliceerde lezing.

2005. Intieme vreemde. Een schrijfboek. Vert. Krijn Peter Hesselink. Amsterdam: Podium.

2006. Thinking Birdness. Winternachten-lezing. Den Haag. Ongepubliceerde lezing.

Coetzee, J. M. 2004 [1991]. Breyten Breytenbach and the reader in the mirror. In Judith Lütge Coullie, J. U. Jacobs (eds.). a.k.a. Breyten Breytenbach. Critical Approaches to his Writings and Paintings. Amsterdam: Rodopi, 75-96. 
Galloway, Francis, 1990. Breyten Breytenbach as openbare figuur. Pretoria: HAUM-Literêr.

Krevelen, Laurens van. 2007. De creatieve bewegingen van een vrije geest. In Breyten Breytenbach. De windvanger. Amsterdam: Podium, 315-22.

$<w w w . g o r e e i n s t i t u t e . o r g>$ Toegang: Augustus 2008.

$<$ www.powerofculture.nl> Toegang: Augustus 2008. 